\title{
Postoperative external beam radiotherapy for locoregional control in iodine refractory differentiated thyroid cancer
}

\author{
Andries H Groen1, Deborah van Dijk¹, Wim Sluiter², Thera P Links², Hendrik P Bij|3 and John T M Plukker1 \\ 1Department of Surgical Oncology, University of Groningen, University Medical Center Groningen, Groningen, the Netherlands \\ 2Department of Endocrinology, University of Groningen, University Medical Center Groningen, Groningen, the Netherlands \\ 3Department of Radiation Oncology, University of Groningen, University Medical Center Groningen, Groningen, the Netherlands \\ Correspondence should be addressed to T P Links or J T M Plukker: t.p.links@umcg.nl or j.t.m.plukker@umcg.nl
}

\begin{abstract}
Background: The role of postoperative external beam radiotherapy (EBRT) in patients with residual iodine refractory-differentiated thyroid cancer (IR-DTC) is still inconclusive. The aim of this retrospective study was to evaluate locoregional control (LRC) and overall survival (OS), and potential side effects after postoperative EBRT for both microscopic and macroscopic non-radically resected, locally advanced IR-DTC.

Methods: Between 1990 and 2016, 49 patients with locally advanced IR-DTC received EBRT for microscopic (R1; $n=28)$ or macroscopic $(\mathrm{R} 2 ; n=21)$ locoregional residual disease. For more insight into the added effect of EBRT, we performed an intrapatient sub-analysis in 32 patients who had undergone more than 1 surgical intervention, comparing LRC after primary, curative-intended surgery with LRC after repeated surgery plus EBRT. To estimate LRC and OS, we used Kaplan-Meier curves. From 2007 onward, we prospectively recorded toxicity data in our head and neck cancer database $(n=10)$. Results: LRC rates 5 years after EBRT were higher for R1 (84.3\%) than for R2 (44.9\%) residual disease $(P=0.016)$. The 5 -year OS rate after EBRT was $72.1 \%$ for $\mathrm{R} 1$ and $33.1 \%$ for R2 disease $(P=0.003)$. In the intrapatient analysis $(n=32)$, LRC rates were $6.3 \%$ 5 years after only initial surgery and $77.9 \%$ after repeated surgery with EBRT $(P<0.001)$. Acute toxicity was limited to grade I and II xerostomia, mucositis, and hoarseness; only one patient developed late grade III dysphagia.

Conclusions: Postoperative EBRT is associated with long-lasting LRC and OS with acceptable toxicity in patients with locally advanced IR-DTC, especially in microscopic residual disease.
\end{abstract}

\section{Introduction}

Patients with differentiated thyroid cancer (DTC) commonly have a good prognosis, with 10-year survival rates of $80-95 \%$ (1). In $10-20 \%$ of the patients, recurrences occur within 5 years after initial surgical treatment followed by radioactive iodine (131) and thyroid-stimulating hormone suppression therapy $(2,3,4)$.
Key Words
- differentiated thyroid cancer
- radiotherapy
- locoregional control
- side effects
- survival

However, $15-33 \%$ of DTC patients have a primary iodine refractory-differentiated thyroid cancer (IR-DTC) or develop IR-DTC after several sessions of ${ }^{131}$ I therapy $(5,6$, 7,8 ), as defined in the American Thyroid Association (ATA) guidelines (4). The ineffectiveness of 131 therapy is related to a loss of iodine uptake or sodium iodide symporter 
expression and activation of the mitogen-activated protein kinase pathway $(8,9)$. IR-DTC is commonly correlated with advanced disease, a high tumor burden, and multiple metastases along with a less-differentiated tumor state (6).

The value of external beam radiotherapy (EBRT) has been studied mainly in locally advanced DTC, but not specifically evaluated in IR-DTC patients $(10,11,12,13,14)$. The ATA Guidelines recommend surgery combined with ${ }^{131}$ I and/or EBRT for unresectable DTC involving the upper aerodigestive tract (4). However, the indications for EBRT remain inconsistent because of some contradictory results $(15,16,17,18,19)$, especially in cases involving microscopic residual (R1) disease. Though prospective data are lacking, recent retrospective studies have reported beneficial effects of EBRT on selected patients $(20,21,22)$. Based on these results, EBRT after final incomplete resections of IR-DTC may offer locoregional control (LRC) and probably overall survival (OS), although radiation-related morbidity after extensive repeated surgery will probably influence the quality of life (23).

The aim of this study was to evaluate LRC and OS after postoperative EBRT for both microscopic and macroscopic non-radically resected, locally advanced IR-DTC and to assess the potential side effects.

\section{Materials and methods}

Between January 1990 and October 2016, in our tertiary referral center, we included 49 patients who had locally advanced IR-DTC and had received postoperative EBRT for LRC of residual disease. The IR-DTC patients were divided according to the four categories in the ATA guidelines: (i) the malignant/metastatic tissue does not ever concentrate radioiodine (no uptake outside the thyroid bed at the first diagnostic or therapeutic whole body scan); (ii) the tumor tissue loses the ability to concentrate radioiodine after previous evidence of RAI-avid disease (in theabsence ofstable iodine contamination); (iii) radioiodine is concentrated in some lesions but not in others; (iv) metastatic disease progresses despite significant concentration of radioiodine (4). Next, we used the Charlson Comorbidity Index (CCI) score, which predicts long-term survival in patients with multiple comorbidities based on patients' disease status and past medical history (24).

Adequate initial surgery consisted of total thyroidectomy en bloc with resection of infiltrated surrounding structures (strap muscles, jugular vein, esophageal external muscular wall, or pretracheal fascia) and modified or radical lymph node dissection when indicated. A subset of 35 patients underwent more than 1 surgical intervention. As the dates of initial surgery were missing for 3 patients, we performed an intrapatient analysis among 32 patients, comparing the LRC after curative-intended surgery with LRC after revision surgery plus EBRT to get more insight into the added effect of EBRT. We performed this study according to national Dutch guidelines at the time of inclusion. Based on the design of the study, the Institutional Review Board waived approval.

\section{Staging and pathologic findings}

To determine the extent of the disease at the time of initial presentation and restaging, we used the tumor node metastases (TNM) according to the eighth edition of the American Joint Committee on Cancer for DTC (25). Local tumor extension and distant metastases were recorded before radiation based on 18F-fluorodeoxyglucose PET (18F-FDG-PET) and MRI scans, also used for targeting tumor volume. Re-examination of the resected specimens by an experienced pathologist $(\mathrm{BvH})$ confirmed our pathological findings. Pathologic radicality of the final resection was defined as $\mathrm{R} 1$ if microscopic tumor was present at the resection margins and as $\mathrm{R} 2$ if macroscopic tumor remained.

\section{Radiotherapy}

The indication for postoperative EBRT in all patients was decided after discussion in the institutional multidisciplinary tumor board. Until 2008, EBRT was delivered with3D-conformal radiotherapy (3D-CRT; $n=26$ ), using six MegaVoltage photon beams from three different directions (one anterior field and two bilateral fields) to focus precisely on the tumor, while avoiding the healthy surrounding tissue. From 2008 onward, intensitymodulated radiotherapy (IMRT; $n=23$ ) with sevenfield equidistant non-opposing beams was used. IMRT patients were treated with a simultaneous integrated boost technique, by delivery of different dose levels to different target volumes within a single treatment fraction. After R1 resection or extranodal spread, the surgical bed was treated to a total dose of $52.8 \mathrm{~Gy}$ in 33 fractions of $1.6 \mathrm{~Gy}$ with a simultaneous integrated boost to the high-risk areas up to $66 \mathrm{~Gy}$, in fractions of $2 \mathrm{~Gy}$. In cases with $\mathrm{R} 2$ resections, we treated the surgical bed to $54.25 \mathrm{~Gy}$ in fractions of 1.55 Gy. The boost dose to the macroscopic residual disease was
This work is licensed under a Creative Commons Attribution-NonCommercial-NoDerivatives 4.0 International License.ifica.com at 04/26/2023 11:02:22AM 
70 Gy in fractions of 2 Gy. No additional elective radiation therapy was applied to the neck or upper mediastinum.

\section{Follow-up}

Patients received regular follow-up with serum thyroglobulin measurement, clinical examination, US and CT/MRI, and/or 18F-FDG-PET/CT upon clinical suspicion. Progression of locoregional disease was defined as any increase in size of residual tumor and/or suspected regional nodal metastases, usually confirmed by cytohistological examination. Suspicious radiographic lesions outside the cervical neck and upper mediastinum were defined as distant metastases. LRC and OS were determined from the end of radiotherapy until progression of locoregional disease and until death or last follow-up, respectively.

\section{Toxicity}

Baseline, early (6-12 weeks), and late (>12 weeks) radiation-induced side effects were assessed regularly in a standardized head and neck follow-up program. From 2007 onward, toxicity data of all DTC patients referred for EBRT were prospectively recorded according to the RTOG/ EORTC Radiation Morbidity Scoring Criteria (26), using the head and neck cancer module (EORTC QLQ-H\&N35).

\section{Statistics}

Clinical endpoints were LRC and OS. Kaplan-Meier estimates were performed for survival, and the logrank test used to compare survival curves. Comparisons between cohorts were performed using the chi-square test or Fisher's exact test; medians were compared using the Mann-Whitney $U$ test. A $P$-value $<0.05$ was considered as statistically significant. Statistical analyses were performed using IBM SPSS for Windows version 26 (SPSS Inc.).

\section{Results}

\section{Patient and treatment data}

Patient and tumor characteristics are given in Table 1. Mean age was 66.7 years (s.D., 12.4), with a median CCI of 5 (interquartile range (IQR), 4-7) and median follow-up of 45 (IQR, 25-79) months after EBRT. Microscopic residual disease was present in 28 patients (57.1\%), and macroscopic residual disease was present in 21 patients (42.9\%). At the time of radiation, 27 patients $(55.1 \%)$ had synchronous regional metastases and 14 patients (28.6\%) had distant metastases. Extrathyroidal extension was present in 29 patients $(59.2 \%)$.

Table 1 Patient and tumor characteristics.

\begin{tabular}{|c|c|c|c|c|}
\hline Patient characteristics & All patients $(n=49)$ & $\begin{array}{c}\text { Patients with microscopic } \\
\text { residue }(n=28)\end{array}$ & $\begin{array}{c}\text { Patients with macroscopic } \\
\text { residue }(n=21)\end{array}$ & P -value \\
\hline Female & $29(59.2 \%)$ & $17(60.7 \%)$ & $12(57.1 \%)$ & \\
\hline Male & $20(40.8 \%)$ & $11(39.3 \%)$ & $9(42.9 \%)$ & 1.000 \\
\hline Age (years, mean with s.D.) ${ }^{a}$ & $66.7(12.4)$ & $66.9(15.7)$ & $66.5(9.4)$ & 0.424 \\
\hline CCI score (median with IQR)a & $5(4-7)$ & $5(4-7)$ & $6(3.5-6.5)$ & 0.812 \\
\hline Follow-up (months, median with IQR)a & $45.2(24.7-79.2)$ & $60.4(33.0-98.6)$ & $30.9(16.0-52.3)$ & $0.008^{a}$ \\
\hline \multicolumn{5}{|l|}{$\mathrm{TNM}^{\mathrm{b}}$} \\
\hline $\mathrm{T} 1-3 \mathrm{~b}$ & $18(36.7 \%)$ & $10(35.7 \%)$ & $8(38.1 \%)$ & \\
\hline $\mathrm{T} 4 \mathrm{a} / \mathrm{b}$ & $29(59.2 \%)$ & $16(57.1 \%)$ & $13(61.9 \%)$ & \\
\hline $\mathrm{Tx}$ & $2(4.1 \%)$ & $2(7.1 \%)$ & $0(0.0 \%)$ & 0.457 \\
\hline NO (a/b) & $22(44.9 \%)$ & 10 (35.7\%) & $12(57.1 \%)$ & \\
\hline N1 (a/b) & $27(55.1)$ & 18 (64.3\%) & $9(42.9 \%)$ & 0.158 \\
\hline MO & 35 (71.4\%) & 19 (67.9) & $16(76.2 \%)$ & \\
\hline M1 & $14(28.6 \%)$ & $9(32.1 \%)$ & $5(23.8 \%)$ & 0.750 \\
\hline \multicolumn{5}{|l|}{ Pathology } \\
\hline Papillary & 29 (59.2\%) & 15 (53.6\%) & $14(66.7 \%)$ & \\
\hline Follicular & $20(40.8 \%)$ & 13 (46.4\%) & 7 (33.3\%) & 0.394 \\
\hline \multicolumn{5}{|l|}{ IR category } \\
\hline I & 7 (14.3\%) & $2(7.1 \%)$ & $5(23.8)$ & \\
\hline II & 23 (46.9\%) & 14 (50.0\%) & $9(42.9 \%)$ & \\
\hline III & $13(26.5 \%)$ & 10 (35.7\%) & $3(14.3 \%)$ & \\
\hline IV & 6 (12.2\%) & $2(7.1 \%)$ & 4 (19.0\%) & 0.139 \\
\hline
\end{tabular}

age, $\mathrm{CCl}$ score, and follow-up calculated at the start of EBRT. bEighth tumor node metastases classification at initial treatment. $\mathrm{CCl}$, Charlson comorbidity index; IQR, interquartile range; IR, iodine refractory.

https://etj.bioscientifica.com https://doi.org/10.1530/ETJ-21-0033 (c) 2022 The authors Published by Bioscientifica Ltd.
This work is licensed under a Creative Commons Attribution-NonCommercial-NoDerivatives 4.0 International License.ifica.com at 04/26/2023 11:02:22AM 
Except for the duration of follow-up, there were no significant differences between the groups with microscopic and macroscopic residual disease (Table 1). In all patients, treatment consisted of one or more surgical procedures (1-5), with additional ${ }^{131}$ I ablation (Table 2). Fourteen patients received EBRT after primary extensive surgical treatment, and 35 patients after $\geq 2$ surgical procedures. EBRT was delivered with a median dose of 66 (IQR, 60-70) Gy and a median of 33 (IQR, 31-35) fractions. IMRT was applied in 23 patients (46.9\%) and 3D-CRT in 26 patients (53.1\%).

\section{Clinical endpoints}

\section{Locoregional control}

All patients Locoregional relapse was detected in 13 patients $(26.5 \%)$ at a median of 29 months (IQR, 9-42) after EBRT. 1-, 5-, and 10-year LRC rates were 91.2, 71.0, and $59.2 \%$, respectively, for the whole population. Persistent LRC with the appearance of distant metastases outside the radiation field was present in 20 patients.

Patients with $\mathbf{R} 1$ vs $\mathbf{R} 2$ resection 1 -, 5 - and 10-year LRC rates were $92.7,84.3$, and $75.8 \%$ for R1 residual disease, and $88.8,44.9$, and $22.4 \%$ for $\mathrm{R} 2$ residual disease, respectively $(P=0.016$; Fig. 1A).
Intrapatient analysis; surgery vs repeated surgery plus EBRT The effect of EBRT on LRC was further analyzed in an intrapatient subset analysis $(n=32) .1-, 5-$, and 10-year LRC rates were 59.4, 6.3, and $3.1 \%$ after initial surgery, and $93.3,77.9$, and $62.3 \%$ after repeated surgery $(\geq 2)$ plus EBRT, respectively $(P<0.001$; Fig. $1 B)$. One patient after initial surgery and ten patients after repeated surgery $(\geq 2)$ had non-resectable macroscopic disease. Comparable results were found when the same intrapatient subset analysis was performed in patients with only microscopic disease $(n=22) .1-, 5-$, and 10-year LRC rates were 59.1, 4.5, and $4.5 \%$ after initial surgery, and $90.9,80.7$, and $71.8 \%$ after repeated surgery $(\geq 2)$ plus EBRT, respectively $(P<0.001$; Supplementary Fig. 1, see section on supplementary materials given at the end of this article).

\section{Overall survival}

All patients 1-, 5-, and 10-year OS rates after EBRT were $87.8,56.7$, and $25.3 \%$, respectively, for the whole population.

Patients with R1 vs $\mathbf{R} 2$ resection 1-, 5-, and 10-year OS rates were $92.9,72.1$, and $36.1 \%$ in the $\mathrm{R} 1$ group, and 81.0, 33.1, and 8.3\% in the R2 group ( $P=0.003$; Fig. $1 C)$, respectively.

Table 2 Treatment characteristics.

\begin{tabular}{l} 
Characteristic \\
\hline Surgery \\
Total thyroidectomy \\
Lymph node dissection \\
Concomitant \\
Additional \\
Microscopic residual disease \\
Macroscopic residual disease \\
Total surgical interventions \\
1 \\
2 \\
$\geq 3$ \\
Radioactive iodine \\
Number of ablations (median with IQR) \\
Cumulative activity (MBq, median with IQR) \\
EBRT \\
Total dose (Gy, median with IQR) \\
Fractions (median with IQR) \\
IMRT \\
3D-CRT \\
Systemic therapy, TKI
\end{tabular}

$\boldsymbol{n}(\%), n=49$
$49(100.0 \%)$
$42(85.7 \%)$
$17(34.7 \%)$
$25(51.0 \%)$
$28(57.1 \%)$
$21(42.9 \%)$
$14(28.6 \%)$
$16(32.7 \%)$
$19(38.7 \%)$
$3(2-3)$
$12,950(11,100-16,650)$
$66(60-70)$
$33(31-35)$
$23(46.9 \%)$
$26(53.1 \%)$
$3(6.1 \%)$

Gy, gray; IMRT, intensity-modulated radiotherapy; IQR, interquartile range; MBq, megabecquerel; TKI, tyrosine kinase inhibitor; 3D-CRT, 3D-conformal radiotherapy.

https://etj.bioscientifica.com

https://doi.org/10.1530/ETJ-21-0033 (c) 2022 The authors Published by Bioscientifica Ltd.
This work is licensed under a Creative Commons Attribution-NonCommercial-NoDerivatives 4.0 International License.ifica com at $04 / 26 / 2023$ 11:02:22AM 


\section{A}

A Locoregional Progression Free Survival

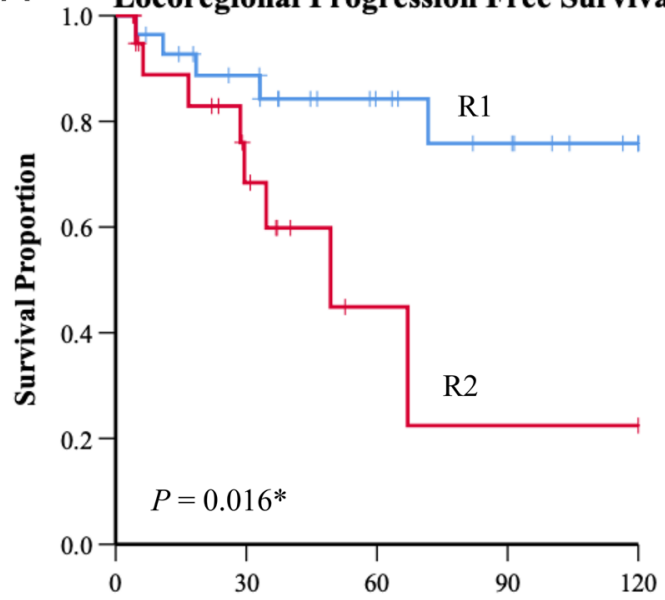

Number at risk

$\begin{array}{rrrrrr}\text { R1 } & 28 & 21 & 12 & 8 & 3 \\ \text { R2 } & 21 & 9 & 2 & 1 & 1\end{array}$

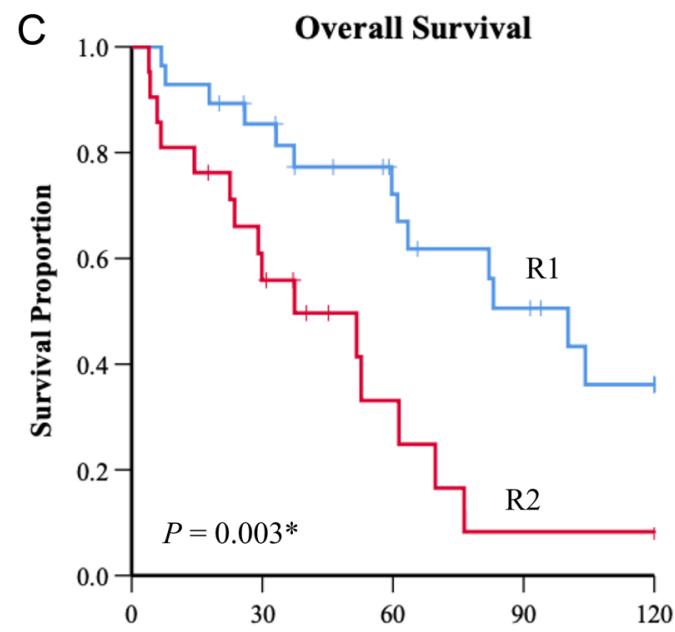

Number at risk

R1

R2

Follow-up (months)

$\begin{array}{rrrr}22 & 14 & 9 & 5 \\ 11 & 4 & 1 & 1\end{array}$

\section{B Locoregional Progression Free Survival}

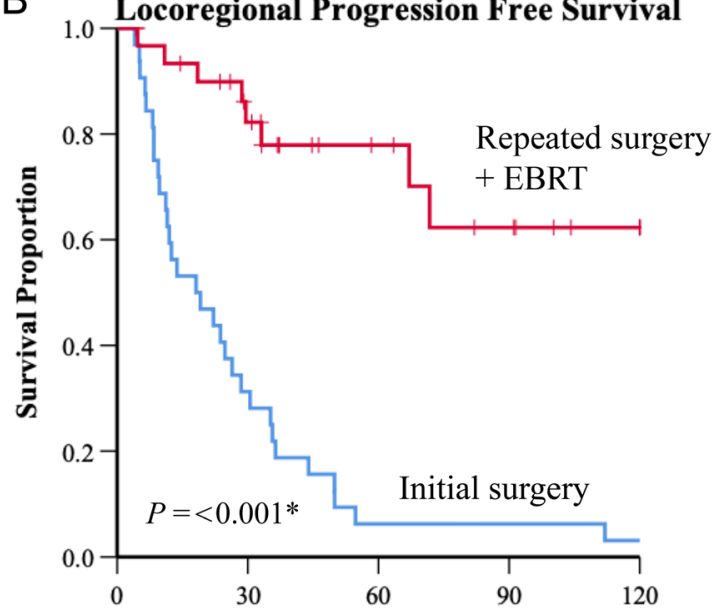

Number at risk

Follow-up (months)

$\begin{array}{llllll}\text { Initial surgery } & 32 & 10 & 2 & 2 & 1\end{array}$

Repeated surgery

$\begin{array}{lrllll}+ \text { EBRT } & 32 & 21 & 11 & 7 & 3\end{array}$

\section{Figure 1}

(A) Kaplan-Meier estimate of locoregional progression-free survival based on microscopic (R1) vs macroscopic (R2) residual disease. Blue line represents R1 disease, and red line represents R2 disease $(P=0.016)$. (B) Kaplan-Meier estimate of intrapatient subset analysis $(n=32)$. Locoregional progressionfree survival based on initial surgical intervention vs repeated surgery plus EBRT. Blue line represents patients treated with initial surgery (pre-EBRT), and red line represents patients after repeated surgery plus EBRT $(P<0.001)$. (C) Kaplan-Meier estimate of overall survival based on R1 vs R2 residual disease. Blue line represents R1 disease, and red line represents R2 disease $(P=0.003)$.

\section{General}

No difference was seen in LRC and OS regarding the TNM status, as well as the radiation technique (3D-CRT vs IMRT). At death $(n=18), 8(16.3 \%)$ patients had local and distant disease, 9 (18.4\%) had only distant metastases, and 1 patient (2.0\%) had only local tumor progression. Distant metastases were commonly detected in the lung (100\%) and bones (27.8\%).

\section{Toxicity}

Radiation-induced toxicity is presented in Table 3. Toxicity was evaluated prospectively in ten patients treated with 
Table 3 Prospectively scored toxicity of 10 out of 49 patients.

\begin{tabular}{|c|c|c|c|c|}
\hline Start of PORT & Grade 0 & Grade I & Grade II & Grade III \\
\hline Xerostomia & $6(60 \%)$ & $3(30 \%)$ & $1(10 \%)$ & $0(0 \%)$ \\
\hline Mucositis & $10(100 \%)$ & $0(0 \%)$ & $0(0 \%)$ & $0(0 \%)$ \\
\hline Dysphagia & $10(100 \%)$ & $0(0 \%)$ & $0(0 \%)$ & $0(0 \%)$ \\
\hline Hoarseness & $5(50 \%)$ & $5(50 \%)$ & $0(0 \%)$ & $0(0 \%)$ \\
\hline Dermatitis & $10(100 \%)$ & $0(0 \%)$ & $0(0 \%)$ & $0(0 \%)$ \\
\hline $\begin{array}{l}\text { Pain (head and } \\
\text { neck) }\end{array}$ & 10 (100\%) & $0(0 \%)$ & $0(0 \%)$ & $0(0 \%)$ \\
\hline \multicolumn{5}{|l|}{$\begin{array}{l}\text { Acute } \\
\text { (<6 weeks) }\end{array}$} \\
\hline Xerostomia & $4(40 \%)$ & $2(20 \%)$ & $2(20 \%)$ & $0(0 \%)$ \\
\hline Mucositis & $9(90 \%)$ & $1(10$ & $0(0 \%)$ & $0(0 \%)$ \\
\hline Dysphagia & $3(30 \%)$ & $2(20 \%)$ & $5(50 \%)$ & $0(0 \%)$ \\
\hline Hoarseness & $4(40 \%)$ & $4(40 \%)$ & $2(20 \%)$ & $0(0 \%)$ \\
\hline Dermatitis & $2(20 \%)$ & $2(20 \%)$ & $6(60 \%)$ & $0(0 \%)$ \\
\hline $\begin{array}{l}\text { Pain (head } \\
\text { and neck) }\end{array}$ & $3(30 \%)$ & $3(30 \%)$ & $4(40 \%)$ & $0(0 \%)$ \\
\hline \multicolumn{5}{|l|}{$\begin{array}{l}\text { Late } \\
\text { ( } \geq 3 \text { months) }\end{array}$} \\
\hline Xerostomia & $5(55.6 \%)$ & $3(33.3 \%)$ & $1(11.1 \%)$ & $0(0 \%)$ \\
\hline Mucositis & $9(100 \%)$ & $0(0 \%)$ & $0(0 \%)$ & $0(0 \%)$ \\
\hline Dysphagia & $4(44.4 \%)$ & $1(11.1 \%)$ & $3(33.3 \%)$ & $1(11.1 \%)$ \\
\hline Hoarseness & $2(22.2 \%)$ & $5(55.6 \%)$ & $2(22.2 \%)$ & $0(0 \%)$ \\
\hline Dermatitis & $5(55.6 \%)$ & $3(33.3 \%)$ & $1(11.1 \%)$ & $0(0 \%)$ \\
\hline $\begin{array}{l}\text { Pain (head } \\
\text { and neck) }\end{array}$ & $4(44.4 \%)$ & $2(22.2 \%)$ & $3(33.3 \%)$ & $0(0 \%)$ \\
\hline
\end{tabular}

PORT, postoperative radiotherapy.

IMRT. Only one patient had late grade III toxicity; no grade IV toxicity occurred.

\section{Discussion/conclusion}

This study shows that postoperative EBRT is associated with long-lasting LRC and OS with acceptable toxicity in patients with locally advanced IR-DTC, especially in microscopic residual disease. The intrapatient analysis, comparing LRC after primary curative-intended surgery with LRC after revision surgery plus EBRT, showed that EBRT potentially enhances LRC.

LRC is an important clinical endpoint, since locoregional progression accounts for significant morbidity, with reduced quality of life. The American Head \& Neck Society recommend EBRT for patients with gross residual or non-resectable locoregional disease, except for patients with limited residual ${ }^{131}$ I-avid disease (27). Although EBRT is more often offered for patients with macroscopic disease, our study showed additional long-term benefits in patients with microscopic residual IR-DTC who had an inevitable higher risk of locoregional failure with no or limited benefit from additional potentially mutilating surgery. This approach is particularly important in the multidisciplinary discussion, as we should be focused on avoiding too extended and mutilating salvage surgery with associated difficulties and increased severe adverse effects, particularly in the irradiated neck.

Data regarding additional EBRT in patients with IR-DTC are still scarce and remain controversial. Furthermore, we should take care that the benefits of EBRT outweigh the associated morbidity. The sub-analysis in our study suggests that EBRT might increase LRC in these patients. However, the effect of EBRT on OS due to a possible altered natural way of progression is difficult to assess without performing a prospective randomized study with inclusion of a control group not receiving EBRT.

Two retrospective studies from the Memorial Sloan Kettering Cancer Center showed that patients with gross residual and extrathyroidal extension or unresectable DTC, who underwent EBRT with or without low dose concurrent chemotherapy, had an increased LRC $(13,22)$. Several authors found a beneficial effect on gross residual disease. Chow et al. described a comparable significantly increased LRC after 10 years (63.4\% vs $24.0 \%)$ with an increase of cancer-specific survival ( $74.1 \%$ vs $49.7 \%$ ) by adding EBRT in non-radically resected gross residual thyroid cancer (28). Brierley et al. showed an increased LRC in patients with pT4 disease and no gross residual disease after EBRT as compared with patients without EBRT (10-year LRC $86.4 \%$ vs $65.7 \%$ ) (15). Recently, Kim et al. reported a 5-year LRC rate of $95 \%$ in the EBRT group and $63 \%$ in a nonmatched control group, in locally advanced PTC invading the trachea after surgical resection (20). However, others reported no beneficial effects $(16,17,18,29)$. Furthermore, these retrospective observational studies do not include prospective data with proper control groups not receiving EBRT (30).

Therefore, we currently rely on relatively small heterogeneous retrospective cohorts. Thus, when additional surgery involves a high risk of decreased quality of life, EBRT is still considered for a selected group of patients with high likelihood of microscopic residual disease and low likelihood of responding to ${ }^{131} \mathrm{I}$. As discussed at multidisciplinary tumor board meetings, to obtain a better LRC, the decision to use EBRT is based on pre- and postoperative imaging, usually PET-CT and/ or MRI, as well as intraoperative findings by experienced surgeons.

IMRT offers clear dosimetric advantages on tumor coverage and organ sparing above 3D-CRT, reducing late toxic effects, such as long-term xerostomia, without compromising the tumor dose (31). However, reduced toxicity from IMRT is difficult to be demonstrated in this retrospective study, since toxicity data were not

This work is licensed under a Creative Commons Attribution-NonCommercial-NoDerivatives 4.0 International License.ifica.com at 04/26/2023 11:02:22AM 
prospectively collected in the pre-IMRT era. Most studies report these complications retrospectively but seldom consider that these patients have undergone multiple operations and high doses of ${ }^{131} \mathrm{I}(32,33)$.

In this study, EBRT was given in a carefully selected patient population, indicating its strength with clearly stated selection criteria for administering EBRT. However, this selection bias may also be considered as a limitation for generalizability of the results. Although we collected radiotherapy side effects prospectively since the introduction of IMRT, our study is limited by its small cohort with respect to the toxicity data. Furthermore, there is lack of data to include a matched control arm, and the effect of the extent of each surgical resection in itself could not be assessed. Although the intrapatient analysis of LRC should be interpreted with caution, it supports the beneficial effect of EBRT especially since the frequency of macroscopic disease is higher after repeated surgery plus EBRT.

In order to make appropriate decisions for IR-DTC patients in clinical practice, the meaningful impact of EBRT should be considered, as well as novel-targeted drugs including tyrosine kinase inhibitors (TKIs) and immunotherapy $(34,35)$. To identify patients with a high likelihood of harboring iodine refractory disease, several specific descriptions of IR-DTC have been added to the definition, and these patients should be considered as potential candidates for early intervention $(36,37)$. As such, the indication for this systemic approach is generally limited to progressive disease with distant metastases. However, the potentially beneficial effect of combining TKIs with EBRT seems to be a promising new therapeutic strategy for these patients (38). Although relatively rare, we should be aware of bleeding and development of tracheo-oesophageal fistulas in patients treated subsequently with TKIs after radiotherapy (39). Valerio et al. showed that EBRT was not significantly associated with the development of fistulas and organ perforation (40). Therefore, we should be cautious to consider TKI treatment too early after EBRT and refrain radiotherapy in poor performance stated patients particularly in the unresectable cases with extended local invasion.

In summary, the effectiveness of postoperative EBRT was demonstrated by a durable LRC with acceptable toxicity for IR-DTC, especially in patients with microscopic residual disease. To improve LRC, these patients should be referred to specialized centers, where multidisciplinary teams should consider postoperative EBRT when in doubt about the best treatment strategy.
Supplementary materials

This is linked to the online version of the paper at https://doi.org/10.1530/ ETJ-21-0033.

\section{Declaration of interest}

The authors declare that there is no conflict of interest that could be perceived as prejudicing the impartiality of the research reported.

\section{Funding}

This work did not receive any specific grant from any funding agency in the public, commercial, or not-for-profit sector.

\section{Statement of ethics}

This study was performed according to Dutch national guidelines (https:// english.ccmo.nl/). Based on the study design, the Institutional Review Board waived approval.

\section{Data availability statement}

The data that support the findings of this study are not publicly available due to their containing information that could compromise the privacy of research participants but are available from the corresponding author ( $\mathrm{T}$ M P).

\section{Author contribution statement}

Andries H Groen: conceptualization, data curation, formal analysis, investigation, methodology, project administration, validation, visualization, and writing of original draft (including review and editing); Deborah van Dijk: conceptualization, data curation, investigation, methodology, validation, visualization, and writing (including review and editing); Wim Sluiter: conceptualization, investigation, methodology, supervision, validation, and writing (and review and editing); Thera $\mathrm{P}$ Links: conceptualization, data curation, investigation, methodology, project administration, supervision, validation, and writing (and review and editing); Hendrik P Bijl: conceptualization, data curation, investigation, methodology, project administration, supervision, validation, visualization, and writing (and review and editing); John T M Plukker: conceptualization, data curation, investigation, methodology, project administration, supervision, validation, and writing (and review and editing).

\section{Acknowledgements}

The authors like to thank B M van Hemel (MD), head and neck pathologists in the UMCG and member of our multidisciplinary thyroid tumor board for examination of the resected specimens.

\section{References}

1 Links TP, van Tol KM, Jager PL, Plukker JT, Piers DA, Boezen HM, Dullaart RP, de Vries EG \& Sluiter WJ. Life expectancy in differentiated thyroid cancer: a novel approach to survival analysis. Endocrine-Related Cancer 200512 273-280. (https://doi.org/10.1677/erc.1.00892)

2 Schlumberger MJ. Papillary and follicular thyroid carcinoma. New England Journal of Medicine 1998338 297-306. (https://doi. org/10.1056/NEJM199801293380506)

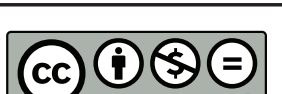

This work is licensed under a Creative Commons Attribution-NonCommercial-NoDerivatives 4.0 International License ifica . com at $04 / 26 / 2023$ 11:02:22Am 
3 Mazzaferri EL \& Kloos RT. Clinical Review 128: Current approaches to primary therapy for papillary and follicular thyroid cancer. Journal of Clinical Endocrinology and Metabolism 200186 1447-1463. (https://doi org/10.1210/jcem.86.4.7407)

4 Haugen BRM, Alexander EK, Bible KC, Doherty G, Mandel SJ, Nikiforov YE, Pacini F, Randolph G, Sawka A, Schlumberger M, et al. 2015 American Thyroid Association management guidelines for adult patients with thyroid nodules and differentiated thyroid cancer. Thyroid 201626 1-133. (https://doi.org/10.1089/thy.2015.0020)

5 Pacini F, Ito Y, Luster M, Pitoia F, Robinson B \& Wirth L. Radioactive iodine-refractory differentiated thyroid cancer: unmet needs and future directions. Expert Review of Endocrinology and Metabolism 20127 541-554. (https://doi.org/10.1586/eem.12.36)

6 Durante C, Haddy N, Baudin E, Leboulleux S, Hartl D, Travagli JP, Caillou B, Ricard M, Lumbroso JD, De Vathaire F, et al. Long-term outcome of 444 patients with distant metastases from papillary and follicular thyroid carcinoma: benefits and limits of radioiodine therapy. Journal of Clinical Endocrinology and Metabolism 200691 2892-2899. (https://doi.org/10.1210/jc.2005-2838)

7 Kloos RT. Approach to the patient with a positive serum thyroglobulin and a negative radioiodine scan after initial therapy for differentiated thyroid cancer. Journal of Clinical Endocrinology and Metabolism 2008 93 1519-1525. (https://doi.org/10.1210/jc.2007-2357)

8 Liu J, Liu Y, Lin Y \& Liang J. Radioactive iodine-refractory differentiated thyroid cancer and redifferentiation therapy. Endocrinology and Metabolism 201934 215-225. (https://doi. org/10.3803/EnM.2019.34.3.215)

9 Buffet C, Wassermann J, Hecht F, Leenhardt L, Dupuy C, Groussin L \& Lussey-Lepoutre C. Redifferentiation of radioiodine-refractory thyroid cancers. Endocrine-Related Cancer 202027 R113-R132. (https://doi. org/10.1530/ERC-19-0491)

10 Keum KC, Suh YG, Koom WS, Cho JH, Shim SJ, Lee CG, Park CS, Chung WY \& Kim GE. The role of postoperative external-beam radiotherapy in the management of patients with papillary thyroid cancer invading the trachea. International Journal of Radiation Oncology, Biology, Physics 200665 474-480. (https://doi.org/10.1016/j. ijrobp.2005.12.010)

11 Terezakis SA, Lee KS, Ghossein RA, Rivera M, Tuttle RM, Wolden SL, Zelefsky MJ, Wong RJ, Patel SG, Pfister DG, et al. Role of external beam radiotherapy in patients with advanced or recurrent nonanaplastic thyroid cancer: Memorial Sloan-Kettering Cancer Center experience. International Journal of Radiation Oncology, Biology, Physics 200973 795-801. (https://doi.org/10.1016/j.ijrobp.2008.05.012)

12 Ibrahimpasic T, Ghossein R, Carlson DL, Chernichenko N, Nixon I, Palmer FL, Lee NY, Shaha AR, Patel SG, Tuttle RM, et al. Poorly differentiated thyroid carcinoma presenting with gross extrathyroidal extension: 1986-2009 Memorial Sloan-Kettering Cancer Center experience. Thyroid 201323 997-1002. (https://doi.org/10.1089/ thy.2012.0403)

13 Romesser PB, Sherman EJ, Shaha AR, Lian M, Wong RJ, Sabra M, Rao SS, Fagin JA, Tuttle RM \& Lee NY. External beam radiotherapy with or without concurrent chemotherapy in advanced or recurrent nonanaplastic non-medullary thyroid cancer. Journal of Surgical Oncology 2014110 375-382. (https://doi.org/10.1002/jso.23656)

14 Tam S, Amit M, Boonsripitayanon M, Cabanillas ME, Busaidy NL, Gunn GB, Lai SY, Gross ND, Sturgis EM \& Zafereo ME. Adjuvant external beam radiotherapy in locally advanced differentiated thyroid cancer. JAMA Otolaryngology: Head and Neck Surgery 2017143 1244-1251. (https://doi.org/10.1001/jamaoto.2017.2077)

15 Brierley J, Tsang R, Panzarella T \& Bana N. Prognostic factors and the effect of treatment with radioactive iodine and external beam radiation on patients with differentiated thyroid cancer seen at a single institution over 40 years. Clinical Endocrinology 200563 418-427. (https://doi.org/10.1111/j.1365-2265.2005.02358.x)

16 Mazzaferri EL \& Young RL. Papillary thyroid carcinoma: a 10 year follow-up report of the impact of therapy in 576 patients. American
Journal of Medicine 198170 511-518. (https://doi.org/10.1016/00029343(81)90573-8)

17 Samaan NA, Schultz PN, Hickey RC, Goepfert H, Haynie TP, Johnston DA \& Ordonez NG. The results of various modalities of treatment of well differentiated thyroid carcinomas: a retrospective review of 1599 patients. Journal of Clinical Endocrinology and Metabolism 199275 714-720. (https://doi.org/10.1210/ jcem.75.3.1517360)

18 Lin JD, Tsang NM, Huang MJ \& Weng HF. Results of external beam radiotherapy in patients with well differentiated thyroid carcinoma. Japanese Journal of Clinical Oncology 199727 244-247. (https://doi. org/10.1093/jjco/27.4.244)

19 Yang Z, Flores J, Katz S, Nathan CA \& Mehta V. Comparison of survival outcomes following postsurgical radioactive iodine versus external beam radiation in stage IV differentiated thyroid carcinoma. Thyroid 201727 944-952. (https://doi.org/10.1089/thy.2016.0650)

20 Kim YS, Choi JH, Kim KS, Lim GC, Kim JH, Kang JW, Song HS, Lee SA Hyun CL, Choi Y, et al. The role of adjuvant external beam radiation therapy for papillary thyroid carcinoma invading the trachea. Radiation Oncology Journal 201735 112-120. (https://doi.org/10.3857/ roj.2017.00192)

21 Sun XS, Sun SR, Guevara N, Marcy PY, Peyrottes I, Lassalle S, Lacout A, Sadoul JL, Santini J, Benisvy D, et al. Indications of external beam radiation therapy in non-anaplastic thyroid cancer and impact of innovative radiation techniques. Critical Reviews in Oncology/Hematology 201386 52-68. (https://doi.org/10.1016/j. critrevonc.2012.09.007)

22 Beckham TH, Romesser PB, Groen AH, Sabol C, Shaha AR MD, Sabra M, Brinkman T, Spielsinger DJ, McBride S, Tsai CJ, et al. Intensity modulated radiation therapy with or without concurrent chemotherapy in non-anaplastic thyroid cancer with unresectable or gross residual disease. Thyroid 201828 1180-1189. (https://doi. org/10.1089/thy.2018.0214)

23 van Nieuwenhuizen AJ, Buffart LM, Langendijk JA, Vergeer MR, Voortman J, Leemans CR \& Verdonck-de Leeuw IM. Health-related quality of life and overall survival: a prospective study in patients with head and neck cancer treated with radiotherapy. Quality of Life Research 202130 1145-1153. (https://doi.org/10.1007/s11136-02002716-x)

24 Charlson ME, Pompei P, Ales KL \& MacKenzie CR. A new method of classifying prognostic comorbidity in longitudinal studies: development and validation. Journal of Chronic Diseases $1987 \mathbf{4 0}$ 373-383. (https://doi.org/10.1016/0021-9681(87)90171-8)

25 Amin MB, Edge S, Greene F, Byrd DR, Brookland RK, Washington MK, Gershenwald JE, Compton CC, Hess KR, Sullivan DC, et al. AJCC Cancer Staging Manual. New York: Springer, 2017.

26 Cox JD, Stetz J \& Pajak TF. Toxicity criteria of the Radiation Therapy Oncology Group (RTOG) and the European Organization for Research and Treatment of Cancer (EORTC). International Journal of Radiation Oncology, Biology, Physics 199531 1341-1346. (https://doi. org/10.1016/0360-3016(95)00060-C)

27 Scharpf J, Tuttle M, Wong R, Ridge D, Smith R, Hartl D, Levine R $\&$ Randolph G. Comprehensive management of recurrent thyroid cancer: an American Head and Neck Society consensus statement: AHNS consensus statement. Head and Neck 201638 1862-1869. (https://doi.org/10.1002/hed.24513)

28 Chow SM, Yau S, Kwan CK, Poon PCM \& Law SCK. Local and regional control in patients with papillary thyroid carcinoma: specific indications of external radiotherapy and radioactive iodine according to T and N categories in AJCC 6th edition. Endocrine-Related Cancer 200613 1159-1172. (https://doi.org/10.1677/erc.1.01320)

29 Jensen MH, Davis RK \& Derrick L. Thyroid cancer: a computer-assisted review of 5287 cases. Otolaryngology: Head and Neck Surgery 1990102 51-65. (https://doi.org/10.1177/019459989010200109)

30 Biermann M, Pixberg MK, Schuck A, Heinecke A, Kopcke W, Schmid KW, Dralle H, Willich N \& Schober O. Multicenter study 
differentiated thyroid carcinoma (MSDS). Diminished acceptance of adjuvant external beam radiotherapy. Nuclear Medicine 200342 244-250. (https://doi.org/10.1055/s-0038-1625735)

31 Nutting C. Radiotherapy in head and neck cancer management United Kingdom National Multidisciplinary Guidelines. Journal of Laryngology and Otology 2016130 (Supplement 2) S66-S67. (https:// doi.org/10.1017/S0022215116000463)

32 Schwartz DL, Lobo MJ, Ang KK, Morrison WH, Rosenthal DI, Ahamad A, Evans DB, Clayman G, Sherman SI \& Garden AS. Postoperative external beam radiotherapy for differentiated thyroid cancer: outcomes and morbidity with conformal treatment. International Journal of Radiation Oncology, Biology, Physics 200974 1083-1091. (https://doi.org/10.1016/j.ijrobp.2008.09.023)

33 Shindo ML, Caruana SM, Kandil E, McCaffrey JC, Orloff LA, Porterfield JR, Shaha A, Shin J, Terris D \& Randolph G. Management of invasive well-differentiated thyroid cancer: an American Head and Neck Society consensus statement. AHNS consensus statement. Head and Neck 201436 1379-1390. (https://doi.org/10.1002/hed.23619)

34 Klein Hesselink EN, Steenvoorden D, Kapiteijn E, Corssmit EP, van der Horst-Schrivers AN, Lefrandt JD, Links TP \& Dekkers OM. Therapy of endocrine disease: response and toxicity of small-molecule tyrosine kinase inhibitors in patients with thyroid carcinoma: a systematic review and meta-analysis. European Journal of Endocrinology 2015172 R215-R225. (https://doi.org/10.1530/EJE-14-0788)

35 French JD, Bible K, Spitzweg C, Haugen BR \& Ryder M. Leveraging the immune system to treat advanced thyroid cancers. Lancet: Diabetes and Endocrinology 20175 469-481. (https://doi.org/10.1016/S22138587(16)30277-7)

36 Berdelou A, Lamartina L, Klain M, Leboulleux S \& Schlumberger M. Treatment of refractory thyroid cancer. Endocrine-Related Cancer 2018 25 R209-R223. (https://doi.org/10.1530/ERC-17-0542)

37 Tuttle RM, Ahuja S, Avram AM, Bernet VJ, Bourguet P, Daniels GH, Dillehay G, Draganescu C, Flux G, Führer D, et al. Controversies, consensus, and collaboration in the use of (131)I therapy in differentiated thyroid cancer: a joint statement from the American Thyroid Association. Thyroid 201929 461-470. (https://doi. org/10.1089/thy.2018.0597)

38 Suzuki K, Iwai H, Utsunomiya K, Kono Y, Kobayashi Y, Van Bui D, Sawada S, Yun Y, Mitani A, Kondo N, et al. Combination therapy with lenvatinib and radiation significantly inhibits thyroid cancer growth by uptake of tyrosine kinase inhibitor. Experimental Cell Research 2021 398 112390. (https://doi.org/10.1016/j.yexcr.2020.112390)

39 Blevins DP, Dadu R, Hu M, Baik C, Balachandran D, Ross W, Gunn B \& Cabanillas ME. Aerodigestive fistula formation as a rare side effect of antiangiogenic tyrosine kinase inhibitor therapy for thyroid cancer. Thyroid 201424 918-922. (https://doi.org/10.1089/ thy.2012.0598)

40 Valerio L, Giani C, Agate L, Molinaro E, Viola D, Bottici V, Matrone A, Puleo L, Lorusso L, Cappagli V, et al. Prevalence and risk factors of developing fistula or organ perforation in patients treated with lenvatinib for radioiodine-refractory thyroid cancer. European Thyroid Journal 202110 399-407. (https://doi.org/10.1159/000514182)

Received in final form 30 November 2021 Accepted 10 December 2021

Accepted Manuscript published online 10 December 2021 (c) 2022 The authors Published by Bioscientifica Ltd.
This work is licensed under a Creative Commons Attribution-NonCommercial-NoDerivatives 4.0 International License.ifica.com at 04/26/2023 11:02:22AM 